\title{
Prevalence and Resistance Profile of Clinical Isolates of Acinetobacter Species from Karachi, Pakistan
}

\author{
Qurat ul Ain, Asma Naim*, Asma Saeed \\ Department of Microbiology, University of Karachi, Karachi, Pakistan
}

ABSTRACT

Acinetobacter baumannii causes a variety of infections including pneumonia, urinary tract infection, bacteremia, peritonitis etc. This organism is developing resistance to a number of antibiotics due to various intrinsic and acquired antibiotic resistance genes. The aim of the present study was to determine the prevalence of antibiotic-resistant Acinetobacter species from Karachi, Pakistan. A total of 111 strains of Acinetobacter baumannii and 8 strains of non-baumannii Acinetobacter were isolated from various hospitals of Karachi from September 2013 to December 2014. Identification of the isolates was based on the standard biochemical tests and detection of OXA-51 and OXA-23. Antibiotic resistance profile of the isolates was determined by Kirby-Bauer disc diffusion method and Minimum Inhibitory Concentration (MIC) was also determined by broth macro-dilution method. Among 111 Acinetobacter baumannii isolates, 8 were pan-drug resistant (PDR) and 103 isolates were multidrug resistant (MDR) while all non-baumannii Acinetobacter were MDR. The effective antibiotics against $A$. baumannii were colistin, gentamicin, trimethoprim/sulfamethoxazole

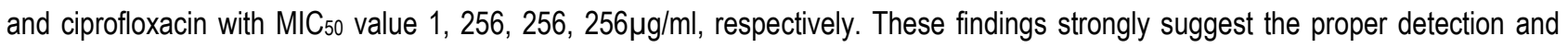
reporting of PDR/MDR Acinetobacter from clinical samples and also the judicious use of broad-spectrum antibiotics is necessary to prevent the further spread of resistant strains of Acinetobacter.

Keywords *Address of Correspondence

Acinetobacter baumannii, OXA-51, minimum inhibitory concentration, pan-

drug resistant, multidrug resistant, broad-

spectrum antibiotics.

Cite this article: Ain $Q$, Naim A, Saeed A. Prevalence and Resistance Profile of Clinical Isolates of Acinetobacter Species from Karachi, Pakistan. RADS J. Biol. Res. Appl. Sci. 2019; 10(1): 6-13.

This is an Open Access article distributed under the terms of the Creative Commons Attribution License (http://creativecommons.org/licenses/by/4.0), which permits unrestricted use, distribution, and reproduction in any medium, provided the original work is properly cited.

\section{INTRODUCTION}

Acinetobacter spp. are gram-negative, aerobic, emerging opportunistic pathogens with an exceptional ability to develop resistance to different groups of antibiotics and associated with a wide range of iatrogenic infections including pneumonia, meningitis, bacteremia, and urinary tract infections ${ }^{1}$. The taxonomy of genus Acinetobacter has been revised extensively and the species level identification by phenotypic characterization is difficult 2 .

Among the Acinetobacter spp., A. baumannii has become one of the top seven pathogens threatening the health care settings, particularly the intensive care setting (ICUs). Because of its remarkable capability to colonize patients in the hospital environment, it causes hospital outbreaks due to cross-transmission between patients ${ }^{3}$. It is also increasingly exhibiting multiple antibiotic resistance and several prevalent strains are resistant to nearly all antibiotics currently in use. Excessive use of antimicrobials in the clinical environment has contributed to the emergence and spread of nosocomial infections. Acinetobacter baumannii presents an array of antibiotic resistance mechanisms which result in limited treatment options for clinicians. Acinetobacter baumannii exhibits resistance by both natural and acquired drug resistance mechanisms. Multidrug-resistant Acinetobacter baumannii (MDRAB) are often associated with co-infection by other pathogenic organisms which make it difficult to determine 
its attributable mortality ${ }^{4}$. In Pakistan, Acinetobacter baumannii has emerged as one of the most common nosocomial pathogen ${ }^{5}$ and there is very limited data regarding the persistence of this notorious organism in developing countries like Pakistan. Due to the higher incidence of nosocomial infections caused by MDRAB, there is a need to pay attention to the detection of this organism within the hospital environment and also in the general population. The present study was designed to determine the prevalence of drug-resistant Acinetobacter baumannii isolates in the clinical settings in Karachi, Pakistan.

\section{MATERIALS AND METHODS}

\section{Bacterial Isolation and Identification}

Along with 111 strains of Acinetobacter baumannii and 8 strains of non-baumannii Acinetobacter species were obtained from various hospitals and diagnostic laboratories of Karachi from September 2013 to December 2014. For this study, strains were collected and inoculated on McConkey's agar, and Gram staining was performed. The pure cultures were maintained on Trypticase soy agar (TSA), stored at $4^{\circ} \mathrm{C}$ and can be available for routine testing.

The isolates were further identified on the basis of the standard biochemical tests including oxidase test, catalase test, temperature growth test $\left(44^{\circ} \mathrm{C}\right)$, glucose fermentation, hemolysis on blood agar, citrate utilization test and gelatin liquefaction 6 . For additional confirmation, OXA-23 and OXA-51 genes were detected by PCR ${ }^{7,8}$ using specific primers (Table 1).
DNA Preparation and PCR Conditions for the Detection of OXA-23 and OXA-51 Genes

The boiling method was used for the DNA preparation, by adding $200 \mu \mathrm{l}$ of endonuclease free water in $1.5 \mathrm{ml}$ Eppendorf tube (Cornell). Take 2-3 colonies of bacteria from Nutrient agar plate to make a suspension in Endonuclease free water. Heat this suspension in a water bath at $90^{\circ} \mathrm{C}$ for 10 minutes. Then cool to ambient temperature ${ }^{24}$. The reaction mixture contains twelve and half microliter Master mix (2x) (Merck), $0.5 \mu$ of reverse primer, $0.5 \mu \mathrm{l}$ of forward primer (IDT, USA) and $9 \mu \mathrm{l}$ of Endonuclease free water were mixed in PCR tubes (Cornell) two and half microliter of DNA template was added in this $22.5 \mu \mathrm{l}$ of reaction mixture (Total volume of reaction mixture in each PCR tube was $25 \mu \mathrm{l}$ ) and subjected to thermocycler and set to perform 30 to 35 cycles.

The isolates possessing these genes were referred to as Acinetobacter baumannii, while only OXA-23 positive strains were categorized as non-baumannii Acinetobacter ${ }^{8}$.

\section{Antibiotic Susceptibility Testing}

The antimicrobial susceptibility profile was determined using the Kirby-Bauer disk diffusion technique according to the protocol of Clinical and Laboratory Standards Institute $(\mathrm{CLSI})^{9}$. Sensitivity to colistin was interpreted according to the criteria defined by Galani and coworkers ${ }^{10}$. A total of 12 antibiotics belonging to seven classes of antibiotics were used in this study including cefepime $(30 \mu \mathrm{g})$, ceftriaxone $(30 \mu \mathrm{g})$, ceftazidime $(30 \mu \mathrm{g})$,

Table 1. Primers and PCR conditions for OXA-51 and OXA-23 genes.

\begin{tabular}{cccccccc}
\hline \multirow{2}{*}{$\begin{array}{c}\text { Target } \\
\text { gene }\end{array}$} & Sequence & Denaturation & Annealing & Extension & $\begin{array}{c}\text { Number } \\
\text { of } \\
\text { cycles }\end{array}$ & $\begin{array}{c}\text { Amplicon } \\
\text { size (bp) }\end{array}$ & Reference \\
\cline { 2 - 6 } $\begin{array}{c}\text { blaOXA- } \\
51\end{array}$ & TAATGCTTTGATCGGCCTTG & $\begin{array}{c}94^{\circ} \mathrm{C} \text { for } 1 \\
\text { minute }\end{array}$ & $\begin{array}{c}50^{\circ} \mathrm{C} \text { for } 1 \\
\text { minute }\end{array}$ & $\begin{array}{c}72^{\circ} \mathrm{C} \text { for } 90 \\
\text { seconds }\end{array}$ & 30 & 353 & 8 \\
\cline { 2 - 6 } $\begin{array}{c}\text { TGGATTGCACTTCATCTTGG } \\
\text { blaOXA- }\end{array}$ & $\begin{array}{c}\text { CTTGCTATGTGGTTGCTTCTC } \\
\text { ATCCATTGCCAACCAGTC }\end{array}$ & $\begin{array}{c}94^{\circ} \mathrm{C} \text { for } 1 \\
\text { minute }\end{array}$ & $\begin{array}{c}50^{\circ} \mathrm{C} \text { for } 1 \\
\text { minute }\end{array}$ & $\begin{array}{c}72^{\circ} \mathrm{C} \text { for } \\
90\end{array}$ & 30 & 650 & 7 \\
\hline
\end{tabular}


cefotaxime (30 $\mathrm{gg})$, trimethoprim/ sulfamethoxazole $(25 \mu \mathrm{g})$, gentamicin $(10 \mu \mathrm{g})$, amikacin $(10 \mu \mathrm{g})$, imipenem

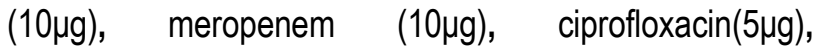

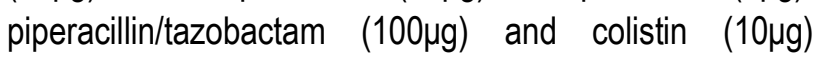
[Oxoid].

\section{Minimum Inhibitory Concentration}

Minimum inhibitory concentration (MIC) of $100 \mathrm{~A}$. baumannii and eight non-baumannii Acinetobacter isolates was determined by broth macro-dilution method using at least one antibiotic from each class including cefotaxime, trimethoprim/ sulfamethoxazole, gentamicin, meropenem, ciprofloxacin, piperacillin/tazobactam, and colistin following the guidelines provided by CLSI ${ }^{9}$. Test concentrations of antibiotics used are mentioned in Table 6. The lowest antibiotic concentration which inhibited growth was considered as the Minimum inhibitory concentration $(\mathrm{MIC})^{2}$.

\section{RESULTS}

In total, 119 Acinetobacter strains were isolated from 160 clinical specimens. Of these, 111 strains were identified as Acinetobacter baumannii and eight were nonbaumannii Acinetobacter with the prevalence rate of $69 \%$ and $5 \%$ respectively. Species identification was confirmed after the successful PCR amplification of OXA-23 and OXA-51 genes. The highest number of isolates were obtained from tracheal aspirates $(62 \%)$ followed by sputum (14\%), pus (9\%), wounds (5\%) and single isolate were recovered from urine, blood, central venous catheter (CVC) tip, endotracheal tubes (ETT) tip, bronchoalveolar lavage (BAL) and peritoneal fluid (Table 2).

A higher frequency of Acinetobacter species was isolated from males (68/111). High-risk age groups ranged from neonates to teenagers whereas patients with the age above fifty also had a higher frequency (Figure 1 and 2). After successful PCR amplification of OXA-23 and OXA51 genes, isolate were easily identified and categorized up to the specie level.

The presence of other organisms in the study samples was also detected and $A$. baumannii was found coexisting with other pathogenic organisms in 30 samples whereas non-baumannii Acinetobacter spp. we're not associated with other pathogens (Table 3 ).
Table 2. Frequency of Acinetobacter baumannii and non-baumannii Acinetobacter species from various clinical samples.

\begin{tabular}{ccc}
\hline & \multicolumn{2}{c}{ No. of isolates (\%) } \\
\cline { 2 - 3 } Specimens & $\begin{array}{c}\text { Acinetobacter } \\
\text { baumannii } \\
\text { (n= 111) }\end{array}$ & $\begin{array}{c}\text { Non-baumannii } \\
\text { Acinetobacter } \\
\text { spp. } \\
(\mathbf{n}=8)\end{array}$ \\
\hline Tracheal aspirate & $69(62)$ & $5(62)$ \\
\hline Sputum & $16(14)$ & $1(12)$ \\
\hline Pus & $9(8)$ & $0(0)$ \\
\hline Wounds & $6(5)$ & $1(12)$ \\
\hline Urine & $2(1)$ & $0(0)$ \\
\hline Blood & $2(1)$ & $1(12)$ \\
\hline CVC tip & $2(1)$ & $0(0)$ \\
\hline ETT tip & $2(1)$ & $0(0)$ \\
\hline BAL & $2(1)$ & $0(0)$ \\
\hline Peritoneal fluid & $1(0.9)$ & $0(0)$ \\
\hline
\end{tabular}

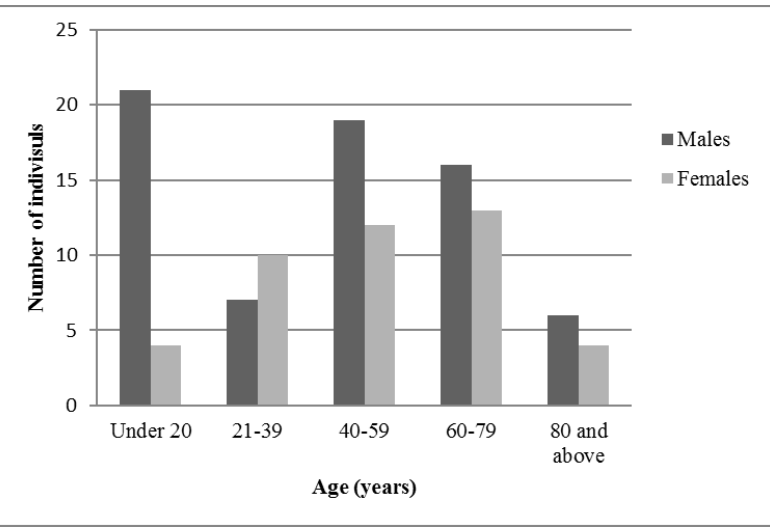

Figure 1. Distribution of age and gender of study population w.r.t. isolation of Acinetobacter baumannii.

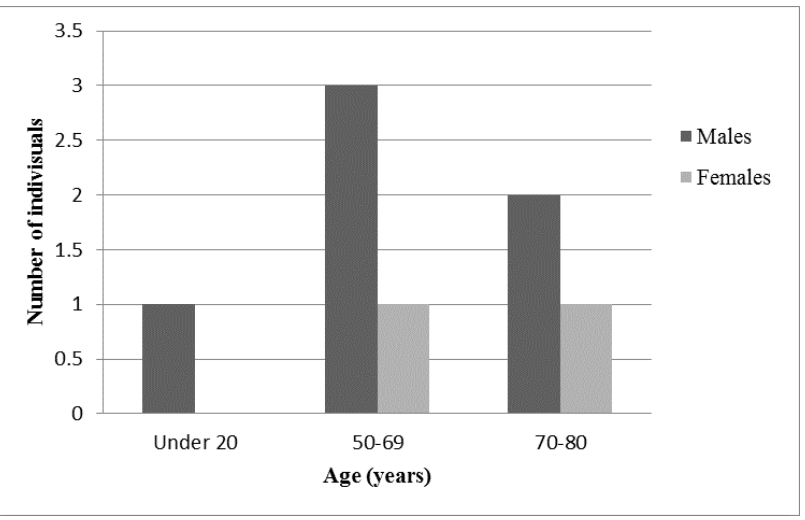

Figure 2. Distribution of age and gender of study population w.r.t isolation of non-baumannii Acinetobacter 
Table 3. Co-infecting organisms in the hospitalized patients.

\begin{tabular}{ccc}
\hline Organisms & No. & $\%$ \\
\hline Methicillin sensitive S. aureus & 2 & 6 \\
\hline Methicillin resistant S. aureus & 5 & 16 \\
\hline Pseudomonas aeruginosa & 7 & 23 \\
\hline Escherichia coli & 3 & 10 \\
\hline Klebsiella pneumoniae & 6 & 20 \\
\hline Streptococcus fecalis & 1 & 3 \\
\hline Burkholderia cepacia & 1 & 3 \\
\hline Enterobacter sp. & 3 & 10 \\
\hline Enterococcus sp. & 1 & 3 \\
\hline Citrobacter freundii & 1 & 3 \\
\hline
\end{tabular}

Table 4. Antibiotic resistance profile of Acinetobacter baumannii by Kirby- Bauer disc diffusion method ( $N=111)$.

\begin{tabular}{|c|c|c|c|c|}
\hline Antibiotic Groups & Name of antibiotic & Symbols (potency) & $\mathbf{S}$ & $\mathbf{R}$ \\
\hline $\begin{array}{c}\text { B-latams } / \beta \text {-lactamase inhibitor } \\
\text { combinations }\end{array}$ & Tazobactam/pipercillin & 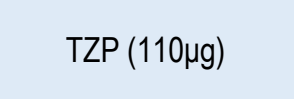 & 0 & 111 \\
\hline \multirow{4}{*}{ Cephems } & Ceftazidine & CAZ $(30 \mu \mathrm{g})$ & 0 & 111 \\
\hline & Cefepime & FEP $(30 \mu g)$ & 0 & 111 \\
\hline & Cefotaxime & СТX $(30 \mu \mathrm{g})$ & 0 & 111 \\
\hline & Ceftriaxone & $\mathrm{CRO}(30 \mu \mathrm{g})$ & 0 & 111 \\
\hline \multirow{2}{*}{ Carbapenems } & Imipenem & IMP $(10 \mu \mathrm{g})$ & 0 & 111 \\
\hline & Meropenem & MEM $(10 \mu \mathrm{g})$ & 0 & 111 \\
\hline Lipopeptides & Colistin & СТ $(10 \mu \mathrm{g})$ & 109 & 2 \\
\hline \multirow{2}{*}{ Aminoglycosides } & Gentamicin & $\mathrm{CN}(10 \mu \mathrm{g})$ & 1 & 110 \\
\hline & Amikacin & AK $(10 \mu g)$ & 0 & 111 \\
\hline Fluoroquinolones & Ciprofloxacin & $\mathrm{CIP}(5 \mu \mathrm{g})$ & 0 & 111 \\
\hline Folate pathway inhibitor & Trimethoprim/ Sulfamethoxazole & SXT $(25 \mu g)$ & 10 & 101 \\
\hline
\end{tabular}


Table 5. Antibiotic resistance profile of non-baumannii Acinetobacter $(\mathrm{N}=8)$.

\begin{tabular}{|c|c|c|c|c|c|}
\hline Antibiotic groups & Name of antibiotic & $\begin{array}{l}\text { Symbols } \\
\text { (potency) }\end{array}$ & $\mathbf{S}$ & I & $\mathbf{R}$ \\
\hline B-latams/ $\beta$-lactamase inhibitor combinations & Tazobactam/ pipercillin & 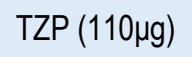 & 1 & 0 & 7 \\
\hline \multirow{4}{*}{ Cephems } & Ceftazidine & $\mathrm{CAZ}(30 \mu \mathrm{g})$ & 1 & 0 & 7 \\
\hline & Cefepime & FEP $(30 \mu \mathrm{g})$ & 1 & 0 & 7 \\
\hline & Cefotaxime & CTX $(30 \mu \mathrm{g})$ & 0 & 1 & 7 \\
\hline & Ceftriaxone & $\mathrm{CRO}(30 \mu \mathrm{g})$ & 0 & 1 & 7 \\
\hline \multirow{2}{*}{ Carbapenems } & Imipenem & $\mathrm{IMP}(10 \mu \mathrm{g})$ & 2 & 0 & 6 \\
\hline & Meropenem & MEM $(10 \mu g)$ & 3 & 0 & 5 \\
\hline Lipopeptides & Colistin & CT $(10 \mu \mathrm{g})$ & 8 & 0 & 0 \\
\hline \multirow{2}{*}{ Aminoglycosides } & Gentamicin & $\mathrm{CN}(10 \mu \mathrm{g})$ & 1 & 0 & 7 \\
\hline & Amikacin & AK $(10 \mu \mathrm{g})$ & 1 & 0 & 7 \\
\hline Fluoroquinolones & Ciprofloxacin & $\mathrm{CIP}(5 \mu \mathrm{g})$ & 2 & 1 & 5 \\
\hline Folate pathway inhibitor & $\begin{array}{c}\text { Trimethoprim/ } \\
\text { Sulfamethoxazole }\end{array}$ & SXT $(25 \mu \mathrm{g})$ & 1 & 1 & 6 \\
\hline
\end{tabular}

Table 6. Minimum inhibitory concentration of Acinetobacter baumannii by broth macro-dilution method ( $\mathrm{N}=100)$.

\begin{tabular}{cccccc}
\hline Antibiotics & Range $(\boldsymbol{\mu g} / \mathrm{ml})$ & MIC & MIC50 & MIC90 & $\begin{array}{c}\text { MBC } \\
(\boldsymbol{\mu g} / \mathbf{m l})\end{array}$ \\
\hline CTX & $0.5-1024$ & $>1024$ & 512 & $>1024$ & - \\
\hline TZP & $0.5-1024$ & $>1024$ & 512 & $>1024$ & - \\
\hline CT & $0.625-16$ & 2 & 0.5 & 1 & 4 \\
\hline CN & $0.5-512$ & $>512$ & 256 & $>512$ & - \\
\hline SXT & $0.5-512$ & $>512$ & 256 & $>512$ & - \\
\hline CIP & $0.25-512$ & $>512$ & 256 & $>512$ & - \\
\hline MEM & $0.25-512$ & $>512$ & 512 & $>512$ & - \\
\hline
\end{tabular}

Table 7. Minimum inhibitory concentration of non- baumannii Acinetobacter spp. by broth macro-dilution method $(\mathrm{N}=8)$.

\begin{tabular}{cccccc}
\hline Antibiotics & Range $(\boldsymbol{\mu g} / \mathbf{m l})$ & MIC & MIC50 & MIC90 & $\begin{array}{c}\text { MBC } \\
(\boldsymbol{\mu g} / \mathbf{m l})\end{array}$ \\
\hline CTX & $0.5-512$ & 512 & 128 & 512 & - \\
\hline TZP & $0.5-512-$ & 512 & 128 & 512 & - \\
\hline CT & $0.625-16$ & 1 & 0.25 & 0.5 & 2 \\
\hline CN & $0.5-512$ & $>128$ & 32 & $>128$ & - \\
\hline SXT & $0.5-512$ & 64 & 32 & 64 & - \\
\hline CIP & $0.25-512$ & 64 & 32 & 64 & - \\
\hline MEM & $0.25-512$ & 64 & 32 & 64 & - \\
\hline
\end{tabular}


All $A$. baumannii strains were resistant to 9 of the 12 antibiotics tested i.e., piperacillin/ tazobactam, ceftazidime, cefepime, cefotaxime, ceftriaxone, imipenem, meropenem, amikacin, and ciprofloxacin while $90 \%$ strains were found resistant to trimethoprim/ sulfamethoxazole and $99 \%$ to gentamicin. Importantly in this study, we observed that two strains were resistant to colistin (Table 4). In case of non-baumannii Acinetobacter all strains were found to be sensitive against colistin, while $75 \%$ were found resistant to trimethoprim/ sulfamethoxazole, $72 \%$ to imipenem, $62 \%$ to meropenem and ciprofloxacin, while $87.5 \%$ to piperacillin/ tazobactam, cefepime, ceftriaxone, ceftazidime, cefotaxime, gentamicin and amikacin (Table 5).

MIC results showed very high level of resistance among A. baumannii against the tested antibiotics except colistin which showed promising results (Table 6). The MIC 50 values for CTX, TZP, CT, CN, SXT, CIP, and MEM were $512 \mu \mathrm{g} / \mathrm{ml}, 512 \mu \mathrm{g} / \mathrm{ml}, 0.5 \mu \mathrm{g} / \mathrm{ml}, 256 \mu \mathrm{g} / \mathrm{ml}, 256 \mu \mathrm{g} / \mathrm{ml}$, $256 \mu \mathrm{g} / \mathrm{ml}$, and $512 \mu \mathrm{g} / \mathrm{ml}$ respectively, and MIC 90 values were $>1024 \mu \mathrm{g} / \mathrm{ml},>1024 \mu \mathrm{g} / \mathrm{ml}, 1 \mu \mathrm{g} / \mathrm{ml},>512 \mu \mathrm{g} / \mathrm{ml}$, $>512 \mu \mathrm{g} / \mathrm{ml},>512 \mu \mathrm{g} / \mathrm{ml},>512 \mu \mathrm{g} / \mathrm{ml}$ respectively. Whereas, in case of non-baumannii Acinetobacter MIC 50 values for CTX, TZP, CT, CN, SXT, CIP, and MEM were $128 \mu \mathrm{g} / \mathrm{ml}, 128 \mu \mathrm{g} / \mathrm{ml}, 0.25 \mu \mathrm{g} / \mathrm{ml}, 32 \mu \mathrm{g} / \mathrm{ml}, 32 \mu \mathrm{g} / \mathrm{ml}, 32$ $\mu \mathrm{g} / \mathrm{ml}$, and $32 \mu \mathrm{g} / \mathrm{ml}$ respectively, while MIC 90 values were $512 \mu \mathrm{g} / \mathrm{ml}, 512 \mu \mathrm{g} / \mathrm{ml}, 0.5 \mu \mathrm{g} / \mathrm{ml},>128 \mu \mathrm{g} / \mathrm{ml}, 64$ $\mu \mathrm{g} / \mathrm{ml}, 64 \mu \mathrm{g} / \mathrm{ml}, 64 \mu \mathrm{g} / \mathrm{ml}$ respectively (Table 7 ).

\section{DISCUSSION}

Due to the increasing reports of the involvement of $A$. baumannii in human infections, it is the most extensively studied among the Acinetobacter species. In recent years, it has become a significant pathogen causing infections with higher morbidity and mortality rate ${ }^{4}$. Other than Acinetobacter baumannii, Stenotrophomonas maltophilia, Pseudomonas aeruginosa, and Burkholderia cepacia complex are the most important clinical aerobic, nonfermenting and Gram-negative rods ${ }^{11}$. The emergence of resistance against major classes of antibiotics has been reported globally. The definition of MDRAB and PDRAB for Acinetobacter varies in the literature. Generally, an isolate is considered MDRAB if it shows resistance to $\geq 3$ classes of antibiotics while PDRAB describes Acinetobacter strains that show resistance to all standard antimicrobial agents (except colistin) ${ }^{12}$. Review of the literature reveals that $A$. baumannii is mostly involved in nosocomial infections, especially the immunocompromised, chronically ill or debilitated individuals or the patients with underlying medical problems such as diabetes and cancer are at higher risk ${ }^{11}$. The local surveillance of drug-resistant organisms in clinical samples enables us to monitor the emergence of opportunistic pathogens and their antimicrobial susceptibility patterns provide the most suitable treatment options. Molecular methods were useful to identify the genus Acinetobacter up to the species level. As OXA-51 gene is intrinsic to $A$. baumannii ${ }^{8}$, plays the key role in the identification. In this study, OXA-51 was also detected for this purpose.

In this study, $7.2 \%$ Acinetobacter baumannii strains were multidrug resistant and $92.7 \%$ pan-drug resistant, moreover two strains were found to be colistin resistant indicating the emergence of colistin resistance, while all strains of non-baumannii Acinetobacter were MDR. The antibiogram of the isolates shows the high resistance profile against almost all antibiotics. In our report, $A$. bauammii were more resistant to antibiotics than nonbaumannii Acinetobacter spp. We observed high MIC values against all tested antibiotics particularly against carbapenems which are considered to be a good choice for Acinetobacter infections. However, in our study high resistance against meropenem $(>512 \mu \mathrm{g} / \mathrm{ml})$ was observed.

Based on other similar studies from Pakistan, it is evident that antibiotic resistance has been increasing among $A$. baumannii strains in our region. Saleem and co-workers reported $21 \mathrm{MDR}$ and 87 PDR strains of Acinetobacter species $^{3}$. A study by Kaleem et al. reported 27 (84.3\%) Metallo- $\beta$ lactamase (MBL) producing $A$. baumannii'13. In another study by Begum et al., 100\% resistance was observed against cephalosporins, fluoroquinolones, carbapenems, and $\beta$ lactam drugs, but minocycline and tigecycline were found to be active against MDR $A$. baumannii'14. In Pakistan (2010) Hasan and colleagues reported 87 MDR isolates, 26 XDR isolates, and 19 PDR A. baumannii isolates from hospitals of Islamabad and Lahore ${ }^{5}$.

Pan-drug resistant $A$. baumannii outbreaks have also been reported from other regions of the world. Fallah et 
al. found a high degree of resistance in A. baumannii isolates against various groups of antibiotics including colistin with $1.8 \%$ resistance ${ }^{15}$. Kou et al. reported 100\% resistance against carbapenems, cephalosporins, fluoroquinolones, and $\beta$ lactam drugs while no resistance against colistin ${ }^{16}$. In a study from China, Wang and coworkers (2018) found that 34 isolates were nonsusceptible to both imipenem and meropenem but a single isolate was resistant to meropenem only. Resistance against other antibiotics was detected as $58.2 \%$ to ceftazidime, $52.2 \%$ to sulbactam, ciprofloxacin $64.2 \%$, and $70.1 \%$ resistance were observed against cotrimoxazole. Whereas, no resistance was found against polymixin and rifampicin, but one isolate was nonsusceptible to minocycline ${ }^{23}$. Büyük et al (2017) reported 84 MDR Acinetobacter strains and these isolates showed resistance against amikacin (50\%), imipenem (58.33\%), moxifloxacin (22.62\%), ciprofloxacin (90.47\%) and rifampicin (47.62\%). While no resistance was found against Colistin and Tigecycline ${ }^{22}$.

In 2013, an Iranian study reported resistance against 21 antibiotics including colistin resistance in $11 \%$ isolates, which is higher than our isolates ${ }^{17}$. Indian research by Badave and Dhananjay (2015) reported, $>84 \% A$. baumannii strains resistant against six antibiotics (ampicillin-sulbactam, piperacillin, amikacin, ciprofloxacin, ceftazidime, and imipenem $)^{18}$. In 2016, Chinese scientists reported multidrug or extensive drug resistance in $72.4 \%$ of the isolates ${ }^{19}$. A study by Solomon reported a high degree of resistance among $A$. baumannii where $>80 \%$ of the isolates were resistant to cefepime, sulfamethoxazole, ciprofloxacin, and ceftriaxone ${ }^{20}$. Our current findings are in accordance with these international reports. Colistin and tigecycline are considered as the last resort drugs against MDRAB. There are increasing reports of colistinresistant $A$. baumannii world-wide which is a growing concern among the medical community as this could lead to treatment failure ${ }^{21}$.

\section{CONCLUSION}

Pan-drug resistant Acinetobacter baumannii infections are life-threatening for neonates and elderly patients. This study shows that clinical isolates of Acinetobacter baumannii are highly resistant to most of the currently used antibiotics. Colistin is the last resort drug for treating
MDRAB infections. Gentamicin and trimethoprim/sulphamethoxazole can be used in combination with colistin. Early detection of Acinetobacter spp. in hospital care settings requires adequate monitoring of the outbreaks using the modern molecular biology, strict infection control that is the most costeffective preventive measure and also to control the indiscriminate use of broad-spectrum antibiotics without any identification of organism and susceptibility testing. However, the lack of standardized laboratory resources makes this an underreported pathogen in developing countries.

\section{REFERENCES}

1. Camp C, Tatum OL. A review of Acinetobacter baumannii as a highly successful pathogen in times of war. Lab medicine. 2010; 41(11):650-7.

2. Looveren VM, Goossens $H$, the ARPAC Steering Group. Antimicrobial resistance of Acinetobacter spp. in Europe. Clin Microb Infect. 2004; 10:684-704.

3. Saleem AF, Ahmed I, Mir F, Ali SR, Zaidi AK. Panresistant Acinetobacter infection in neonates in Karachi, Pakistan. J Infect Dev Ctries. 2010; 4(1):307.

4. Dent LL, Marshall DR, Partap S, Hulette RB. Multidrug resistance Acinetobacter baumannii: a descriptive study in a city hospital. BMC Infect Dis. 2010; 10:196.

5. Hasan B, Perveen K, Olsen B, Zahra R. Emergence of carbapenem-resistant Acinetobacter baumannii in hospitals in Pakistan. J Med Microbiol. 2010; 63(11):50-5.

6. Holt JG, Krieg NR, Sneath PH. A, Staley JT, Williams ST. Bergey's Manual of Determinative Bacteriology. Baltimore: Williams and Wilkins. 1994:787.

7. Mak JK, Kim MJ, Pham J, Tapsall J, White, PA. Antibiotic resistance determinants in nosocomial strains of multidrug-resistant Acinetobacter baumannii. J Antimicrob Chemother. 2009; 63:47-54.

8. Turton JF, Woodford N, Glover J, Yarde S, Kaufmann $M E$, and Pitt $T$ L: Identification of Acinetobacter baumannii by Detection of the blaOXA51-like carbapenemase gene intrinsic to this species. $\mathrm{J}$ of Clin Microb. 2006; 44(8):2974-6.

9. CLSI. Performance Standards for Antimicrobial Susceptibility Testing; Twenty-Second Informational Supplement. CLSI document M100-S22. Wayne PA: Clinical and Laboratory Standards Institute; 2012.

10. Galani I, Kontopidou F, Souli M, Rekatsina P-D, Koratzanis E, Deliolanis J, et al. Colistin susceptibility testing by Etest and disk diffusion methods. Int $\mathrm{J}$ Antimicrob Agents. 2008; 31(5):434-9. 
11. Senkyrikova M, Husickova V, Chroma $M$, Sauer $P$, Bardon $\mathrm{J}$ and Kolar M: Acinetobacter baumannii producing OXA-23 detected in the Czech Republic. SpringerPlus. 2013; 2:296.

12. Munoz-Price LS, Weinstein RA. Acinetobacter infection. N Engl J Med. 2008; 358(12):1217-81.

13. Kaleem F, Usman J, Hassan A, Khan A. Frequency and susceptibility pattern of metallo-beta-lactamase producers in a hospital in Pakistan. Infect Dev Ctries. 2010; 4(12):810-3.

14. Begum S, Hasan F, Hussain S, Shah AA. Prevalence of multidrug-resistant Acinetobacter baumannii in the clinical samples from Tertiary Care Hospital in Islamabad, Pakistan. Pak J Med Sci. 2013; 29(5):1253-8.

15. Fallah $F$, Noori $M$, Hashemi $A$, Goudarzi $H$, Karimi $A$, Erfanimanesh $S$, et al. Prevalence of blaNDM, blaPER, blaVEB, blalMP, and blaVIM genes among Acinetobacter baumannii isolated from two hospitals of Tehran, Iran. Scientific. 2014; doi.org/10.1155/2014/245162.

16. Kuo S, Yang SP, Lee YT, Chuang HC, Chen CP, Chang $\mathrm{CL}$, Chen $\mathrm{TL}$, et al. Dissemination of imipenem-resistant Acinetobacter baumannii with new plasmid-borne blaOXA-72 in Taiwan. BMC Infect Dis. 2013; 13(319):1471-2334.

17. Mohajeri $P$, Farahani A, Feizabadi MM, Ketabi $H$, Abiri R, Najafi F. Antimicrobial susceptibility profiling and genomic diversity of Acinetobacter baumannii isolates: A study in western Iran. Iran J Microbiol. 2013; 5(3): 195-202.

18. Badave GK, Dhananjay K. Biofilm Producing Multidrug-Resistant Acinetobacter baumannii: An Emerging Challenge. J Clin Diagn Res. 2015; 9(1):810.
19. Qi L, Li H, Zhang C, Liang B, Li J, Wang L, Du X, et al. Relationship between antibiotic resistance, biofilm formation, and biofilm-specific resistance in Acinetobacter baumannii. Front Microbiol. 2016; $7: 483$.

20. Solomon FB, Wadilo F, Tufa EG, Mitiku M. Extended spectrum and metalo beta-lactamase producing airborne Pseudomonas aeruginosa and Acinetobacter baumanii in restricted settings of a referral hospital: a neglected condition. Antimicrobial Resistance \& Infection Control. 2017;6(1):106.

21. Cai $Y$, Chai D, Wang R, Liang B, Bai N. Colistin resistance of Acinetobacter baumannii: clinical reports, mechanisms and antimicrobial strategies. J Antimicrob Chemother. 2012; 67(7):1607-15.

22. Büyük $A$, Yilmaz FF, Yurtsever SG, Limoncu $M H$. Antibiotic Resistance Profiles and Genotypes of Acinetobacter baumannii Isolates and In Vitro Interactions of Various Antibiotics in Combination with Tigecycline and Colistin. Turk J Pharm Sci. 2017; 14(1):13-8.

23. Wang $R$, Dorp LV, Shaw LP, Bradley $P$, Wang $Q$, Wang $X$, Jin L, Zhang Q, Liu Y, Rieux A, DoraiSchneiders T, Weinert LA, lqbal Z, Didelot $X$, Wang $\mathrm{H}$ and Balloux $\mathrm{F}$. The global distribution and spread of the mobilized colistin resistance gene mcr-1. Nature Communications. 2018; DOI: 10.1038/s41467-01803205-z.

24. Hujer AM, Hujer KM, Hulten EA, Bajaksouzian S, Adams JM, Donskey CJ, Ecker DJ, Massire C, Eshoo MW, Sampath R, Thomson JM, Rather PN, Craft DW, Fishbain JT, Ewell AJ, Jacobs MR, Paterson DL and Bonomo RA. Analysis of Antibiotic Resistance Genes in Multidrug-Resistant Acinetobacter sp. Isolates from Military and Civilian Patients Treated at the Walter Reed Army Medical Center. J Antimicrob Chemother. 2006; 50(12): 4114-23. 